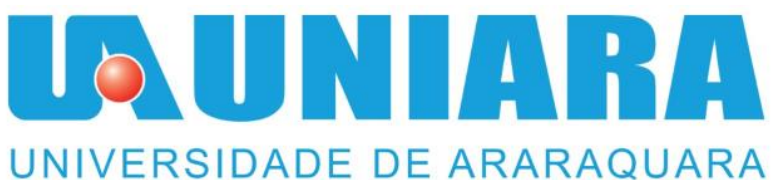

\title{
Controlador de Exportação Energia Elétrica
}

\author{
Alessandro Aparecido Pereira, Engenharia Elétrica, RA-05114005 \\ Uniara Universidade de Araraquara, Departamento de ciências Administrativas e tecnologia, \\ Araraquara-São Paulo pereira-ale@hotmail.com
}

\begin{abstract}
Resumo: Este trabalho tem por finalidade controlar a exportação de energia elétrica da Usina santa cruz, situada em Américo Brasiliense-SP, com capacidade de geração 75MW/H, possui três geradores de $25 \mathrm{MW} / \mathrm{H}$ onde seu controle de exportação é totalmente manual, ou seja o operador necessita atuar constantemente aumentando ou diminuindo a potência do gerador de energia elétrica, para atender a demanda de exportação com a companhia de fornecimento que é de $50 \mathrm{MW} / \mathrm{H}$ além de atender a demanda interna da planta. Sabendo-se que dos três geradores de energia TG-01 e TG-02 são de contrapressão (aumentam/diminuem conforme demanda de vapor de escape do processo), apenas poderá ser aumentado/diminuído a potência do TG03(condensação/extração) para poder atender os 50MW do contrato de exportação, onde nesse será feito uma lógica de controle para poder trabalhar no controle automático.
\end{abstract}

\section{Electric Power Export Controller}

\begin{abstract}
This work aims to control the export of electricity of the Santa Cruz plant, located in Américo Brasiliense, with capacity of generation $75 \mathrm{MW} / \mathrm{h}$, has three generators of $25 \mathrm{MW} / \mathrm{h}$ where its export control is fully manual, ie the Operator has to act constantly increasing or decreasing the power of the electric power generator, to meet the export contract with the supply Company (CPFL) which is $50 \mathrm{MW} / \mathrm{H}$.

Knowing that the three TG-01 and TG-02 power generators are counterpressure (increase/decrease as demand for the exhaust steam of the process), only the power of TG-03 (condensation/extraction) can be increased/decreased to be able to meet the $50 \mathrm{MW}$ of the Export contract, where in this will be done a control logic to be able to work on automatic control.
\end{abstract}

Palavras-chave: Controlador Lógico Programável (PLC), Proporcional Integral Derivativo (PID), Geração de Energia Elétrica. 


\section{INTRODUÇÃO}

A Usina Santa Cruz, situada no Município de Américo Brasiliense-SP possui uma potência instalada de cogeração a biomassa de $75 \mathrm{MW}$, divididos em três (03) turbos geradores, cada um de $25 \mathrm{MW}$ e consumo interno $23 \mathrm{MW}$, sendo duas (02) de contrapressão (TG1 e TG2) e uma de condensação/extração (TG3), exportam energia elétrica na linha de transmissão da companhia (CPFL).

O contrato de exportação entre as empresas é de 50MW/H e por várias vezes essa meta não é alcançada, devido o seu controle ser totalmente manual, dependendo de atuações do operador, dessa forma excede o contrato de exportação, acarretando multas ou não atendendo a demanda estipulada.

Neste contexto, o artigo tem como objetivo controlar a venda de energia elétrica da Usina Santa Cruz, a qual tem contrato com concessionária de energia CPFL (Companhia Paulista de Força) sendo como meta venda 50MW/H, devido a várias oscilações e ser um controle totalmente manual, por vezes essa meta foi ultrapassada, acarretando penalidades

A fim de ter um controle estável, constante, além de proporcionar uma operação mais simples e econômica, torna-se aplicável a utilização de um controle automático para a venda de energia para a concessionaria agindo apenas pela ação das próprias máquinas e controladores. Através de uma lógica PID, controla-se a exportação de energia evitando a operação em modo manual, onde todo controle fica nas mãos do operador, podendo ocasionar possíveis desvios e não sendo preciso o quanto necessário.

Devido as oscilações de processo, alguns motivos justificam a escolha desse projeto, com o não aproveitamento da eficiência dos geradores de energia elétrica e o não atendimento das metas estipuladas em contrato e também para solucionar o problema da geração exceder o limite de exportação. Baseou-se no princípio de controle compensatório onde o TG3, turbina de condensação com extração controlada, fará o papel dinâmico de absorver a demanda excedente ou diminuir a geração.

A lógica consiste em somar as duas potencias ativas exportadas pelas duas subestações que foram denominadas neste estudo como GRID\#1 e GRID\#2 (Redes Primarias de transmissão de energia).

Como problema e hipótese, destacam-se os fatores principais sendo as variações de carga, evidenciando-se os pontos:

- Diminuição / aumento da carga interna da usina;

- Diminuição / aumento do consumo de vapor extração;

- Diminuição / aumento do consumo do vapor de escape;

Estas variações podem promover um fluxo de potência maior que 50MW para a concessionária ocasionando penalidades ou o não atendimento de metas.

Devido ao obstáculo de não ter ganhos seguros na operação do sistema em modo manual, através desse trabalho vamos inserir a lógica LADER no CLP de controle com o intuito de fazer um gerenciamento confiável, sem grandes oscilações onde não precise a atuação do operador. 


\section{REVISÃO BIBLIOGRÁFICA}

A energia, nas suas mais variadas formas e fontes, vem ocupando, de maneira crescente, uma posição de relevância na sociedade contemporânea e cada vez mais se configura como um bem de consumo imprescindível à vida inserida nessa sociedade. O suprimento de energia elétrica é uma das condições indispensáveis para o alcance do desenvolvimento sustentável [7].

Outro processo muito importante na geração é a cogeração que consiste no processo de transformação de energia térmica de um combustível em mais de uma forma de energia útil. Uma das formas que é mais frequentes é a energia mecânica, que é utilizada diretamente no acionamento de equipamentos ou para geração de energia elétrica e a energia térmica que é utilizada diretamente no atendimento das necessidades de calor para processos [9].

A cogeração feita nas usinas de cana-de-açúcar ocorre da seguinte forma: o bagaço ao ser queimado gera energia térmica em forma de vapor e energia elétrica. Em uma fornalha o bagaço é queimado, enquanto o vapor é produzido em uma caldeira, esse vapor gira uma turbina que, por estar interligada ao eixo de um gerador, faz com que o mesmo entre em movimento, e assim gera energia elétrica [9].

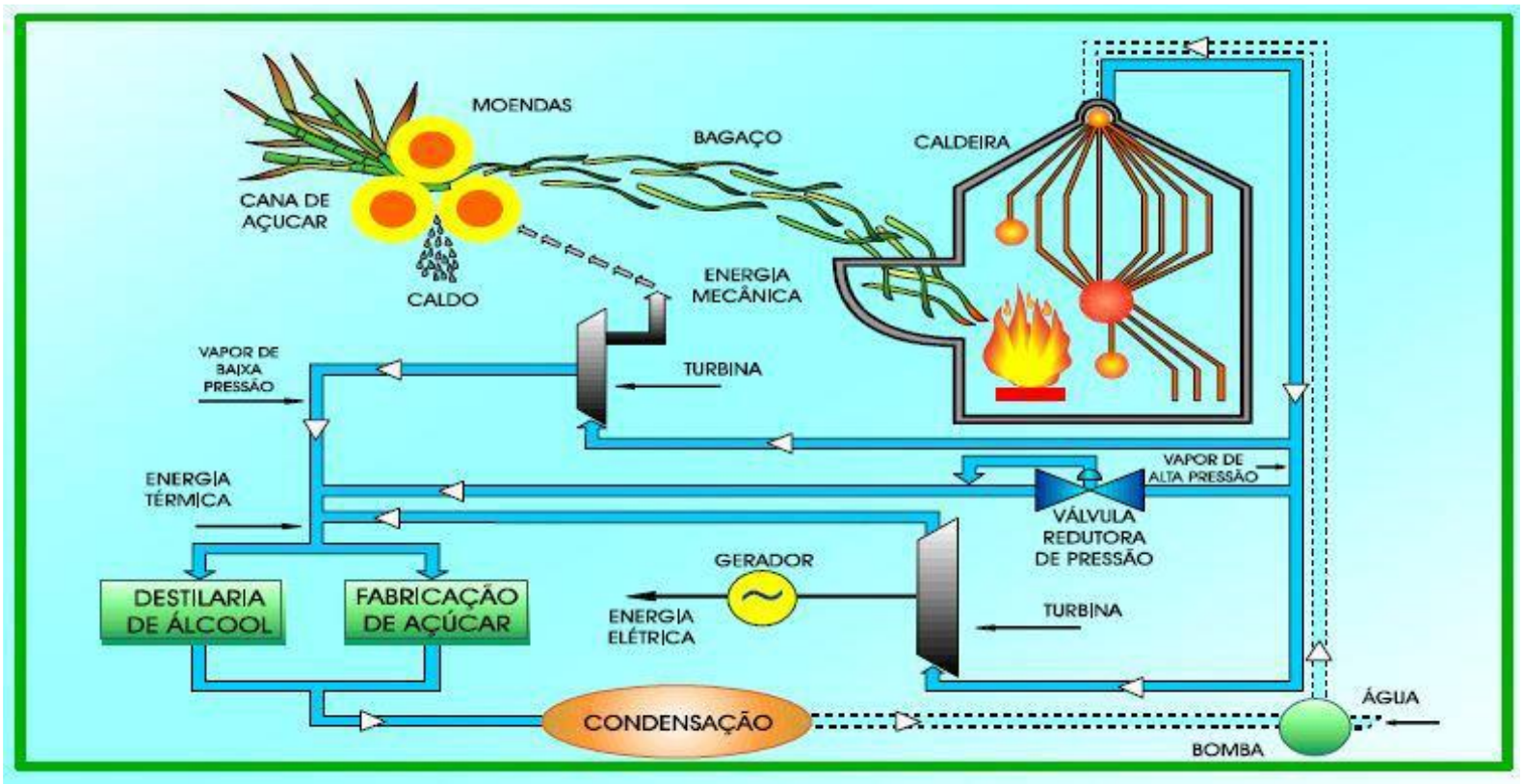

Figura 1. Esquema de Cogeração nas Usinas.

Fonte: CPFL (2007).

Uma ferramenta muito importante na automação das industrias é o PLC, que podemos considerar um computador projetado para trabalhar no ambiente industrial, que tem como finalidade desempenhar funções lógicas, sequenciais, temporização, contagem e aritmética, para controlar, através de entradas e saídas digitais ou analógicas, vários tipos de maquinas ou processos. 
Todo planta industrial necessita de algum tio de controlador para garantir uma operação segura e economicamente viável. Desde o nível mais simples, em que pode ser utilizado para controlar um motor elétrico de um ventilador para regular a temperatura de uma sala, até um grau elevado de complexidade. [1]

Esses sistemas de controle podem ser divididos em três partes com funções bem definidas: os transdutores(sensores), os controladores e os atuadores.

Na programação-LD- Diagrama Ladder, é semelhante a um esquema elétrico funcional, visualmente lembra uma cascata. Os esquemas são compostos estruturalmente de duas linhas verticais e de linhas horizontais, sobe as quais são desenhados os elementos constituintes do sistema a controlar. Cada degrau é chamado de rung. [6]

É composta de uma série de sinais gráficos e resulta preferida pelo programador com conhecimento de lógica eletromecânica porque requer um conhecimento do esquema a relé.

Simbologia Ladder mais utilizadas:

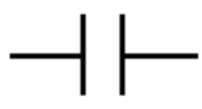

Contato NA

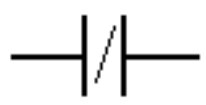

Contato NF

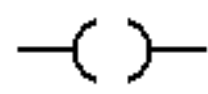

Bobina NA

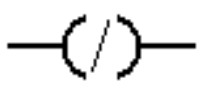

Bobina NC

Já o controle PID consiste em calcular um valor de atuação sobre o processo a partir das informações do valor desejado e valor atual da variável de processo. Onde este valor de atuação sobre processo é transformado em sinal para o atuador utilizado (relé, motor, válvula), e deve garantir controle estável do processo [5].

Definições de siglas e termos:

PV: Variável de processo. ex: temperatura, pressão, vazão, velocidade, etc.

SP: Setpoint. Valor desejado para variável de processo.

MV: Variável manipulada. Variável sobre qual o controlador atua para controlar o processo. ex: posição de uma válvula.

Erro: Diferença entre SV e PV. SV-Pv para a ação reversa e PV-SV para a ação direta

Ação de controle: Pode ser reversa ou direta. Define geralmente a atuação aplicada a MV na ocorrência de variações da PV.

Controlar: atuar sobre uma grandeza de modo que o sistema possua comportamento adequado (estabelecido nas condições de projeto).

Automático: pouca ou nenhuma intervenção do operador.

Manual: o operador precisa sempre assistir o processo.

Planta: objeto (físico ou não) a ser controlado.

Processo: operação da planta a ser controlada.

Objetivos de controlar:

Conforto do operador: ambientes de temp. elevada;

Melhoria da qualidade: Trabalhar ao com melhor eficiência, evitando danos ao equipamento.

Aumento da segurança: ex. Alimentação de chapas em prensas.

Aumento da Produção: Relação de quantidade x tempo. 
Controle: malha aberta e malha fechada.

PID é a composição de 3 ações quase intuitiva, conforme figura.

\begin{tabular}{|l|l|l|}
\hline P & \multicolumn{1}{|c|}{ CORREÇÃO PROPORCIONAL AO ERRO } & $\begin{array}{l}\text { A correção a ser aplicada ao processo } \\
\text { deve crescer na proporção que cresce o } \\
\text { erro entre o valor real e o desejado. }\end{array}$ \\
\hline I & $\begin{array}{l}\text { CORREÇÃO PROPORCIONAL AO } \\
\text { ERRO x TEMPO }\end{array}$ & $\begin{array}{l}\text { Erros pequenos, mas que há muito } \\
\text { tempo existam requerem correção } \\
\text { mais intensa }\end{array}$ \\
\hline D & $\begin{array}{l}\text { CORREÇÃO PROPORCIONAL À TAXA DE } \\
\text { VARIAÇÃO DO ERRO }\end{array}$ & $\begin{array}{l}\text { Se o erro está variando muito rápido, } \\
\text { esta taxa de variação deve ser reduzida } \\
\text { para evitar oscilações. }\end{array}$ \\
\hline
\end{tabular}

O controle por malha PID utiliza o desvio, a diferença, entre o valor esperado de uma variável de processo e seu valor medido por meio de um transdutor.

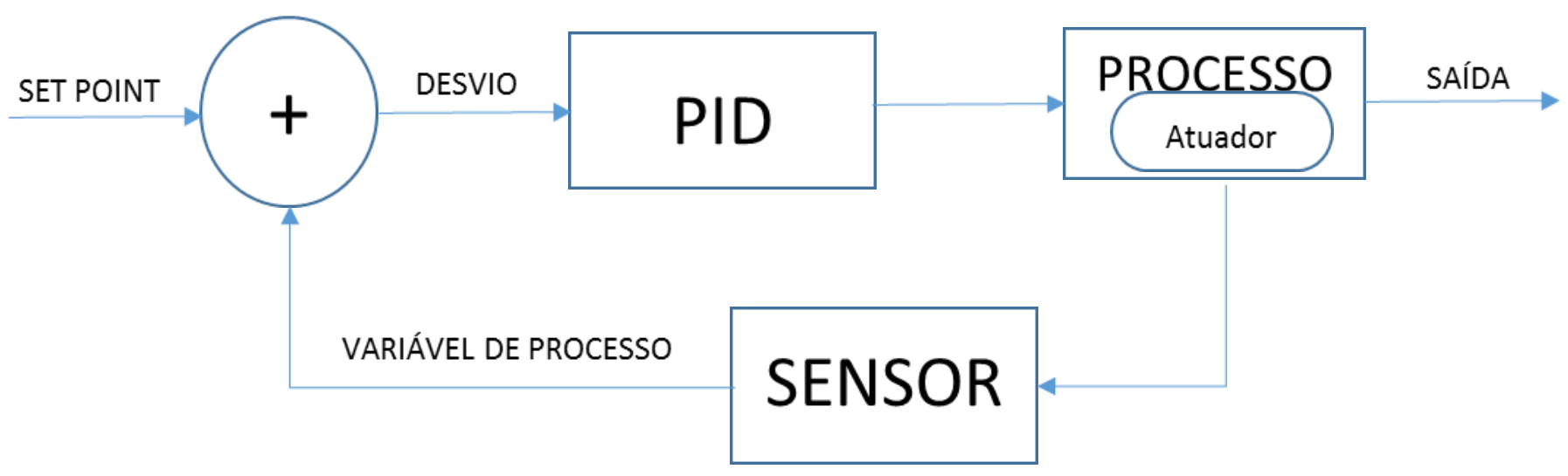

Figura 2- Diagrama de uma malha PID

O PLC Siemens o qual foi aplicado, é estruturado em forma de blocos. Tais blocos são divididos em:

OB - "organization block"

FB - "function block"

DB - "Data block"

FC - "Function" 
OB - Organization Block

Função, matematicamente, é uma regra que relaciona cada elemento de um conjunto (representado pela variável x) a um único elemento de outro conjunto. Assim, para cada um dos elementos de entrada, em função da regra do conjunto que se tenha, pode haver uma ou mais saídas da mesma. No caso do PLC, as instruções de programação são executados seguindo uma frequência de execução (scan), conforme sua criticidade [8].

Assim, em uma lógica onde sua criticidade determine que seja necessário uma velocidade e frequência de execução maior o mesmo pode ser alocado em um scan mais rápido.

A atualização entre entrada (leitura de sinais analógicos e digitais), processar as instruções e atualizar a saída (saídas analógicas e digitais bem como processamento matemático é realizado pelo OB - Organization block.

Outra importante função da OB são as chamadas ou "triggers" que a $\mathrm{OB}$ executa em detrimento a outros blocos como FBs e DBs. Assim se uma lógica declarada não estiver sendo chamado pelo $\mathrm{OB}$, o mesmo não é executado.

FB - Function Block / FC - Function

É o bloco onde se escreve o programa a ser executado. O mesmo pode ser escrito em linguagem ladder, SCL (Structured Control Language) ou FDB (Function Diagram Block).

DB - Data Block

Toda FB/FC executada necessita de um local para armazenamento quer seja permanente ou temporário das variáveis. Quer seja uma constante ou resultado de cálculos aritméticos. Neste bloco é armazenados estas informações que podem ser chamadas por outros FB/FC.

A notação de endereçamento destes dados é estruturada no PLC Siemens como:

DB3AAA.DBDBBB

Onde:

$A A A$ é o nome da DB

$B B B$ é a localização de qual bit, byte ou Word uqe eles esta alocado dentro da DB 


\section{DESENVOLVIMENTO}

Para solucionar o problema da geração exceder o limite de exportação de potencia ativa por conta das variações de consumo interno de energia elétrica ou quer seja variando o consumo de vapor pelo processo, baseou-se no principio de controle compensatório onde o TG3, turbina de condensação com extração controlada, faria o papel dinâmico de absorver a demanda excedente ou diminuir a geração.

A lógica consiste em somar as duas potencias ativas exportadas pelas duas subestações que foram denominadas neste estudo como GRID\#1 e GRID\#2.

Do ponto de vista de automática os mesmos são adquiridos por intermédio dos sinais DB311.DBD1484 e DB311.DBD1512 onde:

DB311.DBD1484 - Potencia Ativa Exportada no Grid \#1;

DB311.DBD1512 - Potencia Ativa Exportada no Grid\#2;

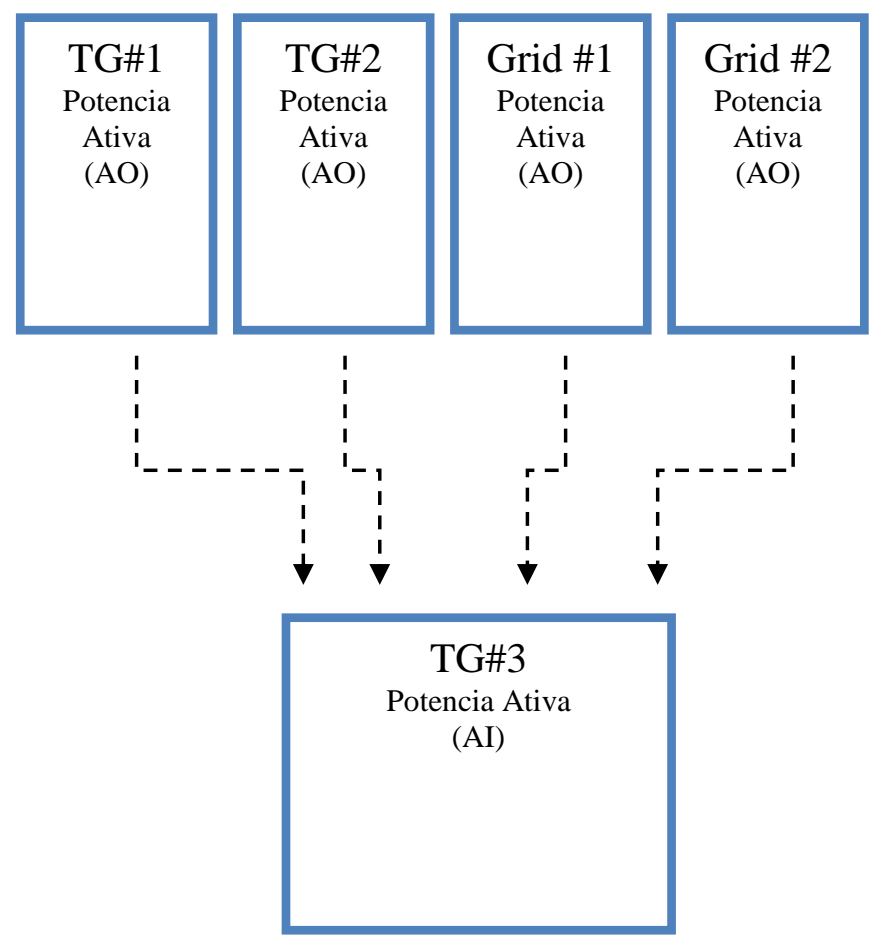

Figura 3. - Esquema de envio dos sinais analógicos entre os painéis da cogeração.

O resultado da somatória das potencias exportadas (MD160) é comparada com um valor limite que poderá se determinado pelo operador, inserido pelo DCS o valor desejado (DB804.DBD2).

Este pop-up para inserção do valor de limite é liberado por intermédio de senha de engenharia do DCS. A cautela e criticidade em alterar estes limites será garantida pela Usina Santa Cruz, por intermédio destes níveis de acesso.

A internalização dos sinais de potencia ativa são realizados por intermédio de sinais analógicos oriundo dos painéis TG\#1; TG\#2; GRID\#1 e GRID\#2 conforme figura 03.

Uma vez que o limite de exportação é alcançado e o controle deste limitador esteja habilitado, esta lógica cria um flag, um sinal digital que determinará a utilização de SP de potência que o TG3 deverá assumir. 


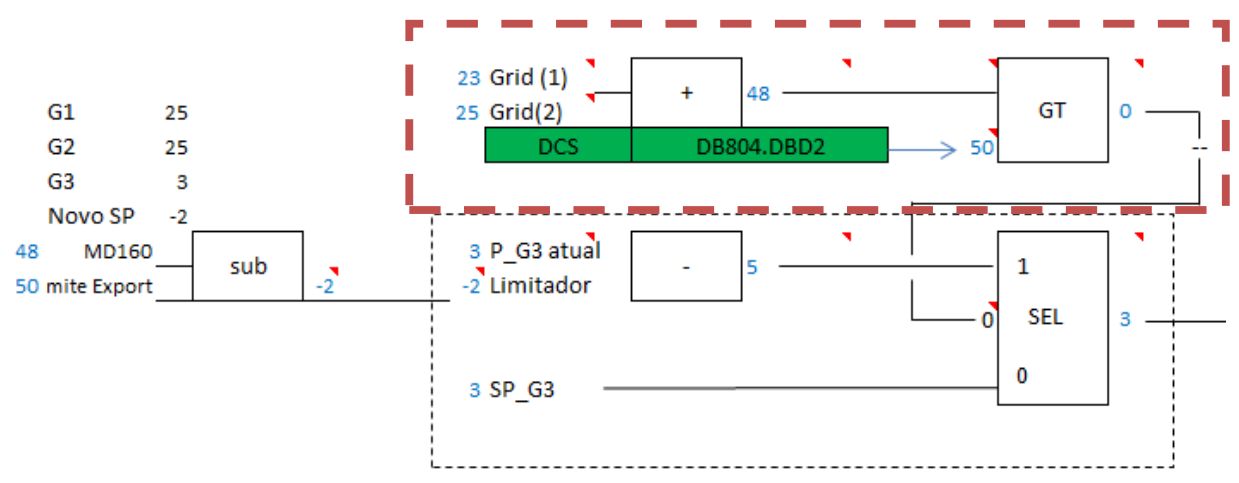

Figura 4. -Medição das potencias exportadas e comparador de nível limite de exportação.

Este limitador demonstrado na figura 4 fará a de-multiplexação do SP a ser aplicado ao governador de velocidade para que o mesmo tenha o comportamento compensatório desejado para que o limite não se exceda.

Considera-se dois SP de potencia a saber:

a) SP_G3 - Set de potencia seguidor, oriundo do DCS. Nesta condição a potencia exportada não excede o limite estipulado pela operação

b) P_G3 Atual Limitador - Set de potencia baseado na diferença (erro) entre potencia exportada e exportação limite. É composta por duas variáveis de controle declaradas (Limitador e P_G3 Atual). O limitador é resultado da diferença entre a potencia exportada total e o limite de exportação, enquanto que o P_G3 atual é o valor da potencia ativa gerada pelo TG3. O resultado destas duas variáveis gera o novo SP que fará com o que o TG3 faça a compensação do excedente de potencia.

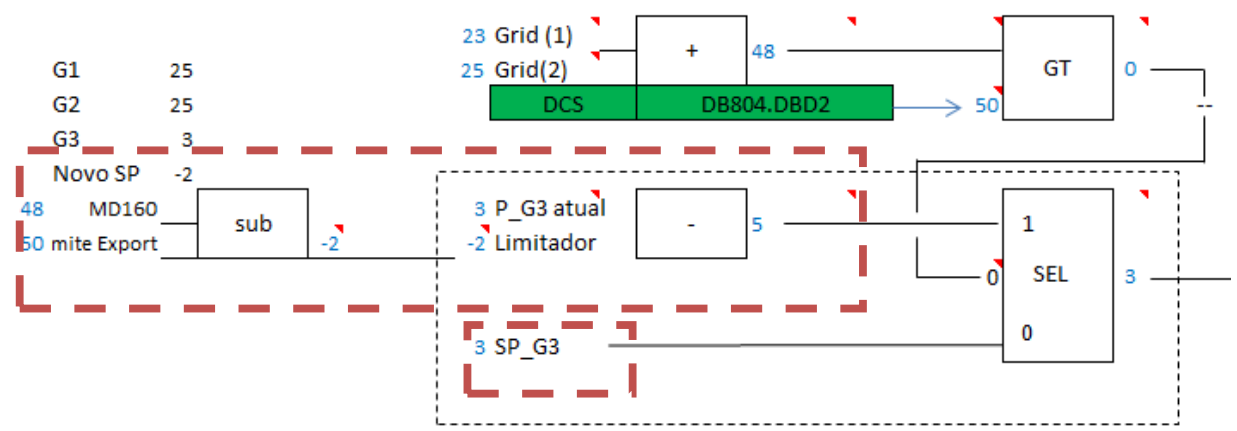

Figura 5. - SP de potencia compensatória e seguidora.

\section{Controle de Pressão de Vapor de Admissão.}

O controle de pressão de vapor de admissão, anteriormente implementado, trabalha em regime de "step control" ou seja, em pequenos passos de ajustes de incremento ou decremento do valor de SP do controle de potência, de modo a obter o efeito de abertura e fechamento da válvula de admissão e assim a manutenção da pressão de vapor vivo.

Sabe-se dos controles instaurados na caldeira, sendo uma delas a de pressão de valor vivo, e que dependendo da amplitude do distúrbio mensurado (variação de pressão / vazão) pode desencadear 
a ação do controlador de pressão da caldeira que por sua vez insere um novo de valor de processo o qual o controle de pressão de vapor de admissão da turbina pode também atuar.

Este evento deflagra uma retroalimentação positiva, no âmbito de controle, que causa instabilidade e uma amplificação constante das variáveis de potencia gerada e pressão de admissão. Este cenário de instabilidade pode promover situações de processo de ambas plantas (caldeira e turbina) onde sistema de proteção poderão atuar retirando os dois sistemas de linha e por consequência prejuízo operacional da planta como um todo.

O "step control" visa obter uma estabilidade, atuando de maneira suave e dentro da banda morta (dead band) do controle da caldeira. Faz-se necessário um ajuste conjunto das duas variáveis de controle, quer seja da caldeira quanto da turbina para que não coexista esta instabilidade.

Como descrito, o controle de pressão de vapor de admissão atua sobre a variação do SP de carga a ser assumida pelo governador. A correção frente ao valor mensurado (PV) e o valor desejado (SP) fará a válvula fechar ou abri de modo a manter a pressão de admissão constante. Este controle é iterado, portanto à lógica de geração de SP de carga para o governador Woodward 505.

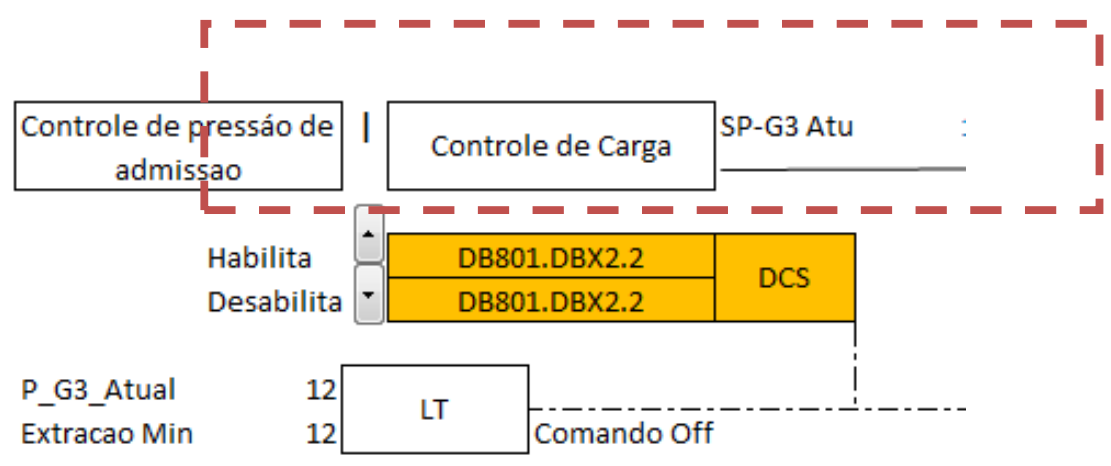

Figura 6 - Controle de pressão de admissão iterado ao controle de carga.

A ação do controle de pressão de admissão altera o SP de controle de carga que promoverá o fechamento da válvula de controle de admissão para manutenção da pressão de vapor vivo e assim a perda de geração de potencia ativa. Entretanto esta atuação de controle possui um limite que fora estipulado como o do limiar da extração. Ou seja: a correção da pressão de vapor vivo deverá ser realizado pela lógica, porem não devera prejudicar o processo.

Este controle não possui sobremaneira intenção de substituir a ação humana da operação bem como a analise do processo e sua tomada de decisão, mas tem por objetivo realizar pequenas correções até que o operador identifique a causa raiz da perda de pressão de vapor vivo e execute as ações pertinentes.

Para tanto a lógica é desabilitada e deixa de atuar no controle de carga quando a potência chegar no limiar do controle de extração. Assim, garante-se que a tentativa de correção da pressão de admissão seja limitada até o limite do desligamento da extração, salvaguardando o processo.

O limitador de potencia de exportação e o limitador de pressão de vapor de admissão poderão trabalhar isolados ou concomitantemente.

Para isso, qual seja o valor de SP calculado e considerado para ser enviado ao governador Woodward 505, considera-se sempre o de menor valor o que garantirá a estabilidade do processo. 


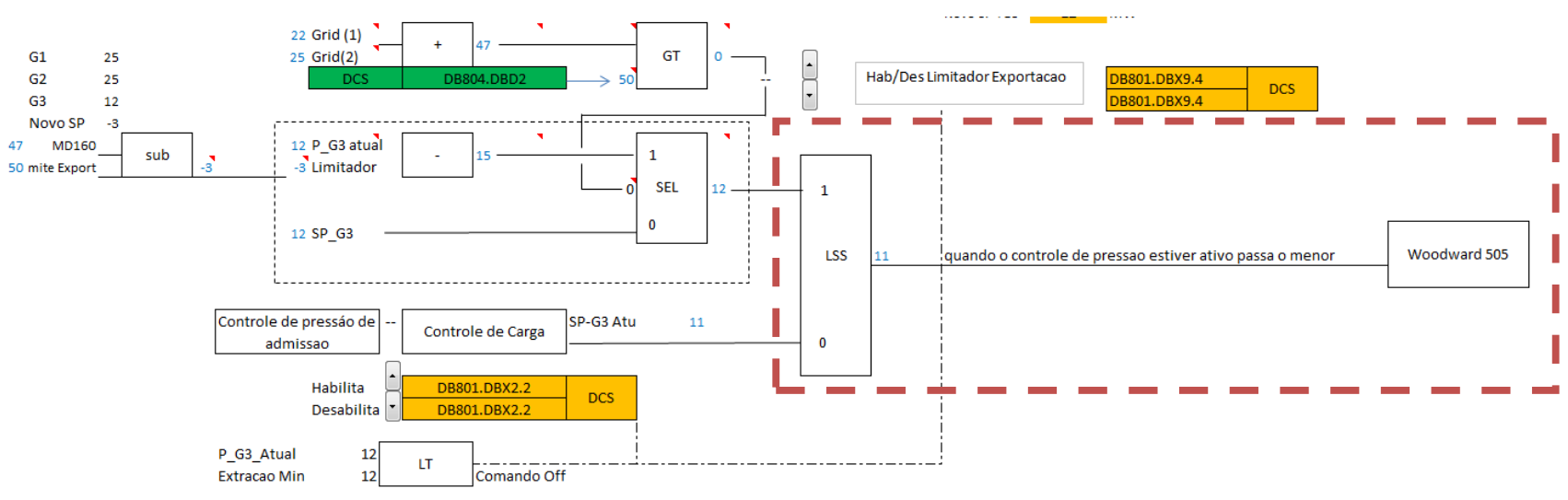

Figura 7. - Seletor de mínimo SP.

Observa-se portanto que as tratativas de SP são trabalhadas de modo a enviar ao controlador de velocidade/potencia, o novo valor de potencia de geração a ser seguido de modo a atender a demanda de consumo interno e exportação.

\section{RESULTADOS}

No gráfico abaixo ainda com o controle de exportação em modo manual podemos observar na linha de cor vermelha a venda de energia com grandes variações, distantes da meta estipulada de 50MW/H, e a potência do TG-03 linha azul com carga baixa, ou seja o operador poderia aumentar a carga para melhorar a exportação de energia.

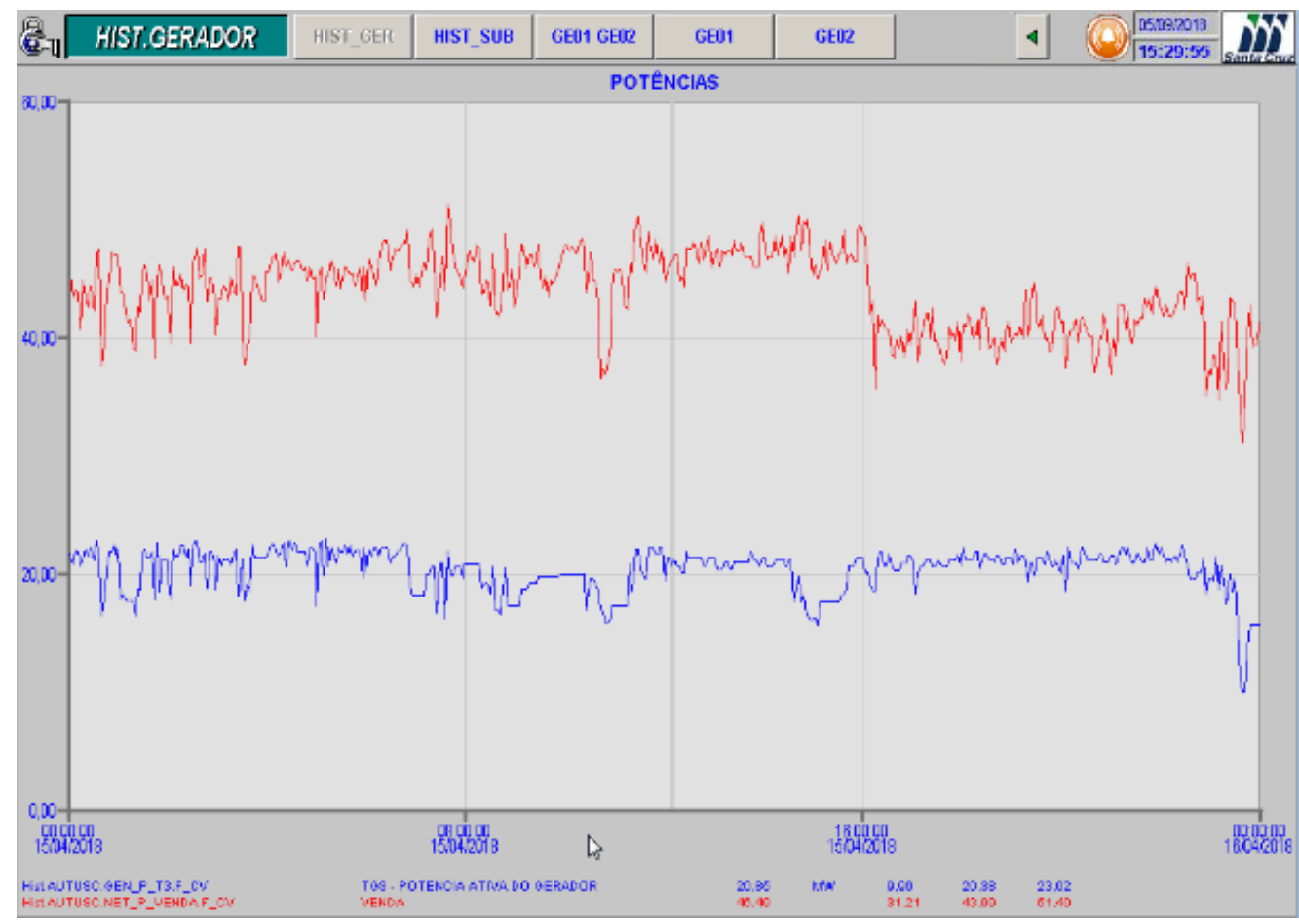

- Gráfico de exportação de energia Elétrica Antes da implementação do controle 
Logo após a implantação do controle automático de exportação podemos observar a venda de energia com variação de amplitude menor e bem mais próxima da meta estipulada, também o TG-03 varia muito mais buscando um SET-POINT de máximo da máquina.

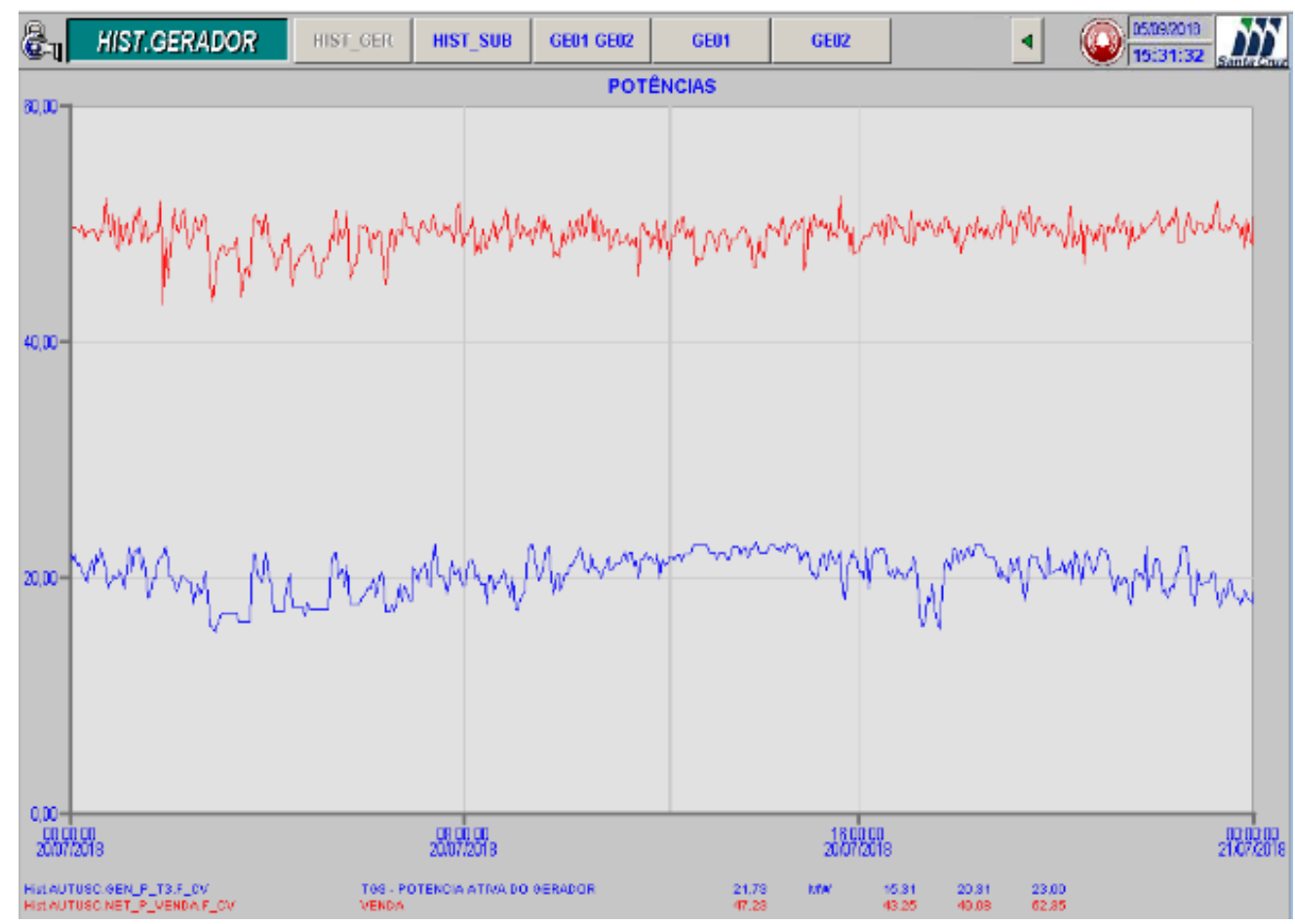

- Gráfico de exportação de energia Elétrica após implementação do controle

\section{CONCLUSÃO}

O controle de exportação implementado executa em tempo real as correções necessárias no SP (set point) de potencia para que o mesmo não transponha os valores de contrato de potência controlando com êxito sua exportação de energia.

Em função das variáveis operacionais da usina como consumo de vapor pelo processo, bem como a busca de estabilidade de geração, a dinâmica de geração pode oscilar operando com uma rápida e sensível reação do contrador de potencia, bem como pode ter um a grande inércia de resposta.

Este cenário é que dificulta ao operador, que de forma manual necessita antever as ações de diminuição ou aumento de potencia de modo que a demanda instantânea de geração de energia possa atender ambos cenários.

Para uma implementação futura deste controle automático, que possui uma reação proporcional à dinâmica do processo, pode-se retrabalhar a taxa de mudança deste SP em conjunto com a dinâmica de resposta do regulador Woodward 505, oferecendo assim uma operação mais suave de geração. Com isso abre-se paralelamente um novo campo de estudo a fim de determinar-se os ganhos ótimos para atender concomitantemente tais variáveis de processo, 
geração, além de ser necessário considerar-se as dinâmicas e respostas dos elementos de controle da maquina primaria (turbina a vapor).

\section{REFERENCIAS}

[1] FRANCHI M. CLAITON, CAMARGO A. L. VALTER, 2008- Controladores Lógicos Programáveis

[2] FRANCHI M. CLAITON, 2013-Controle de Processos Industriais

[3] HINRICHS, R. A. 2011- Energia e meio ambiente

[4] <https://www.researchgate.net/publication/313799597>

Uso_da_Biomassa_para_a_Geracao_de_Energia

[5] OGATA, KATSUHIKO, 2011- Engenharia de controle moderno

[6] PRUDENTE FRANCESCO,2007- Automação industrial

[7] REIS, L.B. Geração de energia elétrica. São Paulo: Manoele,2003

[8] SIEMENS, 2017 - Curso S7 Básico / Avançado

[9] TIAGO F. C. (2011). Cogeração de energia atráves do bagaço de cana-de-açúcar. Trabalho de conclusão de curso de graduação, UFSC, São Carlos,SP, Brasil.

[10] WOODWARD, 2012 - Manual regulador de velocidade Wopdward 505E

[11] CHAPMAN J. STEPHEN, 2013-Fundamentos de Maquinas elétricas 